\title{
Death and dying: elderly persons' experiences of grief over the loss of family members
}

\author{
Eucebious Lekalakala-Mokgele* \\ School of Health Care Sciences, Sefako Makgatho Health Sciences University, Pretoria Gauteng, South Africa \\ *Email: sebi.lekalakala@smu.ac.za
}

Background: Death is one of life's few certainties and a universal experience for all individuals. When death occurs there is usually an impact on the family and friends of the deceased, the magnitude of which often depends on whether death was expected or unexpected. The grieving experiences of the elderly are rarely discussed. The purpose of this study was to describe experiences of grief and reactions to the death of family members amongst the elderly.

Methods: A qualitative phenomenological approach was used to obtain data from elderly women in Ga-Rankuwa, Gauteng, to gain insight into the experiences of grief in this age group. Purposive sampling was used to conduct in-depth interviews with 10 elderly women whose family members had died. The data were analysed using a thematic approach.

Results: The findings show that the elderly were exposed to multiple deaths of family members. The participants helplessly experienced with sorrow the death of family members, had experienced death anxiety, and relinquished control to God in terms of deaths.

Conclusions: The response to death of the elderly affirms that it cannot be assumed that multiple death experiences establish their readiness or ability to handle these experiences and to grieve successfully. It can be concluded that the grieving process of the elderly is not different from any other age group and that they will also require the type of support and assistance considered for younger persons in times of grieving.

Keywords: death anxiety, God's control, grieving, helplessness, sorrow

\section{Introduction}

Death is one of life's few certainties and a universal experience for all individuals; hence all persons with loved ones will eventually become bereaved. ${ }^{1}$ Ageing and time are uncompromising as they always lead to death, which is a natural part of life and happens every day. When death occurs, there is usually an impact on the family and friends of the deceased, the magnitude of which often depends on whether the death was expected or unexpected. ${ }^{2,3}$ Loved ones are left behind to go through the grieving process.

The emotions related to grief are specific to the individual, his/ her relationship with the deceased, and the time and manner of death, amongst other contributing factors. According to Gijzen et $\mathrm{al}_{1}{ }^{4}$ when a child dies the grieving experience is enormous and affects everybody, including other family members. The grieving experiences of the elderly, however, are rarely heard.

Each person's grief is unique and does not follow any pattern or trajectory. ${ }^{5}$ Although each person's grieving process is unique, there are certain patterns that develop for many. For example, grief reactions expressed in the form of crying, fear and anger are so common as to be deemed universal. ${ }^{4}$ There is a paucity of research on the experience of grieving amongst the older African population. The importance of cultural considerations is stressed when evaluating individuals with complicated grief. ${ }^{6}$

Most bereaved people are able to overcome their grief, but in $10 \%$ of cases grief becomes prolonged or complicated. ${ }^{7}$ The
2011 study by Newson et $\mathrm{al}^{8}$ found a higher prevalence of complicated grief in the age range of 75 to 85 years, suggesting that the very elderly have more difficulty in coping with a loss. In a population study amongst the elderly those between the ages of 75 and 84 years had a greater risk of developing complicated grief compared with a younger age group. ${ }^{9}$

The impact of the death of family members on the elderly has received little attention. Yet findings indicate that $10 \%$ of all elderly parents have had an adult offspring die after the parent reached the age of 60 years. Specifically, older adults experience the widest variety of bereavement and grief in terms of type of relationship to the deceased. ${ }^{6}$ The literature has shown that when parents lose their children, or any young family member, the grief is never-ending. ${ }^{4}$

The transition to widowhood is often considered amongst the most stressful transitions in later life. ${ }^{10}$ For older adults who have been married for years, it is difficult to remember life before a spouse, and even harder to create a new life after losing him or her. The literature also shows that the elderly go through multiple losses during their lifespan, including loss of spouses, friends and other family members. ${ }^{11}$

Death is the most obviously permanent and extreme form of loss $^{12}$ yet few studies have considered the impact of repeated bereavements, especially amongst the elderly. This study describes the experiences of grief of older women whose family members have died. Family members lost include their parents, siblings and children. 


\section{Purpose}

The purpose of this study is to describe experiences of grief and reactions to the death of family members amongst the elderly.

\section{Methodology}

A qualitative phenomenological approach was used to obtain data. Qualitative research explores phenomena under scrutiny by focusing on the participants, and it is committed to the participants' viewpoint. ${ }^{13}$ Permission to conduct the study was obtained from Sefako Makgatho University Research and Ethics Committee (Reference number: MREC/H/305/2013).

The researcher is active in the community activities of the elderly, and visited luncheon clubs to recruit participants. A slot was given to the researcher at the end of the monthly meeting at each club in order for her to introduce herself and explain the purpose of the research. After explaining the study to eligible potential participants, the chairperson of each luncheon club notified those who were willing to participate that they would be contacted by the researcher to set up a suitable time and venue for conducting in-depth interviews. All males and females were invited to participate. Given the nature of caring, which is female-dominated, only females volunteered to participate in the study.

The population of this study was purposively selected to include elderly in the community of Ga-Rankuwa, as they would best contribute the information needed for the study. ${ }^{14}$ A purposively selected group of 10 elderly older persons from three luncheon clubs in Ga-Rankuwa participated in the study. This sample size was determined when data saturation was achieved. ${ }^{15}$ The sample was selected on the basis of the following criteria: age of 60 years or more, and having experienced the death of a family member. In-depth individual interviews were conducted with 10 elderly female participants aged between 60 and 87 years. Interviews were conducted by the researcher experienced in qualitative research. A trained research assistant assisted with writing field notes and recording of interviews. An open-ended interview guide was used for the interviews. The guide was developed in English and translated into Setswana, a local language spoken by most participants in the study site. Interviews which lasted for about 45-60 minutes were conducted in Setswana as requested by participants, and were audio recorded with the participants' permission.

Information sessions took place prior to the interviews, and participants were given an assurance of confidentiality and asked to sign consent forms. Participants were informed that they had the right to withdraw from participating in the study at any stage should they wish to do so. Two nurses with counselling and background in psychiatry were on standby at the venue to provide emotional support should this be required. The participants were collected from a common place (social clubs) and were remunerated R10.00 for transport to the club and back to their homes.

The data were analysed using a thematic approach, which aims to understand an issue by revealing the prominent themes at various levels in a text in order to provide a holistic account of the data. ${ }^{16}$ Multiple readings of the transcripts were carried out by the researcher to familiarise herself with content and meaning. It is important that the researcher has a comprehensive understanding of the content and this is done when the researcher is fully immersed and actively engaged in the data. This step provides the foundation for the subsequent analysis. ${ }^{17}$
The analysis was conducted by the author and the co-coder (an expert in qualitative research) who read the transcripts independently and jointly reviewed emerging themes to reach consensus on the interpretation of the data. The data were then analysed manually to identify emerging themes and subthemes that reflected the perceptions and experiences of the participants. This was followed by developing a code list which was used to develop themes.

\section{Findings}

Five themes emerged from the interviews: Cumulative exposures to family members' deaths; the sorrow of watching them die; death anxiety; putting emotions of family members first; and spiritual and religious issues. These are discussed under separate subheadings below.

\section{Cumulative exposures to family members' deaths}

The findings show that these elderly participants had experienced many family members' deaths and had responded in different ways to their grief. These participants had experienced, amongst others, the death of their own parents, siblings and children during their advancing age. Although they were sorrowful when family members died, this emotion was evoked more when their relatives suffered pain before death. The loss of children devastated them most of all:

If it's not my mother, it's my son or my sister or my brother who is sick, and all these people I took care of them, but they all died and I'm left alone. When it came to my son I even cried and said 'God take me rather, replace this child's life with mine, spare him so that together with his wife they will be able to raise their children. I'm already old, please take my life and spare my son.' He was my only child, he did everything for me. (72-year-old)

My sister died in 2009. She said 'There's something that is moving in my body, hold me', and I touched her next to her heart and she said [it] as I was holding her. I thought she had fainted only to find that she slid down, and as she was sliding she died, just like that. That's one of the things that is killing me, even right now." (69year-old)

I closed both my daughter and son's eyes and called the mortuary to come and collect them within one year. I felt the pain later, asking myself the question, why did they die within such a close range of each other? But I said to myself, maybe because he saw that I'm taking care of the sister, he was afraid to tell me that he's also sick. (83-year-old)

\section{The sorrow of watching them die}

All of the participants expressed their pain at observing their family members deteriorate until death at home or in hospital and were struck by grief at their inability to help them:

There's nothing [more] painful than hearing your mother screaming at night. When that pain comes in, she was screaming, and she would say 'You know the way, this pain is so severe'. That voice is still on my mind. Every time when I think about her and that cry, I don't feel good at all. She was 89. (63-year-old)

When she started going to Steve Biko [Academic Hospital] it was after six weeks, she got worse. When she came from 
radiotherapy she developed sores inside her mouth. When she started developing sores inside her mouth she stopped eating. For three months she went without anything in her stomach. It was so painful to watch my daughter suffer. I was even afraid to eat in front of her. (64-year-old)

This thing is so painful, your own mother telling you that she's now dying, and there's no help that can make her get better. You will feel the pain when the person suffers during her illness, because when she suffers it affects all of you. (65-year-old)

\section{Anxiety about impending death}

Participants who have observed their family members whose health did not improve experienced anxiety over their pending deaths:

I went back home. As I was entering my street I said to myself 'In this street there has been tents for funerals before, but in my house there has never been a tent'. And I said, 'In fact why am I thinking such a thing?'. (60year-old)

I always get stressed when I think about the moment he was telling me about the stars and asking me to leave the washing and go to sleep, even when I think about his hiccup. (74-year-old)

One participant expressed her anxiety at her son's impending death through denial:

I said 'You are going nowhere, l'd rather be the one who dies instead'. And he replied 'There's no way, if it's my time to die, how can you be the one who dies before me? If it's time and then I have to go.' I said 'You are going nowhere'. [Participant breaks down crying] (79year-old)

\section{Putting emotions of family members first}

The participants' sorrow was expressed privately, as they felt that they needed to protect the dying and the surviving family members' emotions:

When I cry I was hiding myself from these children, I mean my grandchildren. I had to be strong for them, they have just lost their mother. I'm all by myself, because if you cry and the children cry too, it becomes chaotic. (84-year-old)

I was hurting a lot, the pain that I felt. When I was with her, I was pretending to be strong, but as soon as I leave her, I cried. I felt the pain deeply, but if I'm with her I try to compose myself so that she cannot see that I'm hurting. When you are with her you try by all means to pretend and to downplay her thought of wanting to die at home. I would say to her 'Mother, you won't die now'. (71-year-old)

I will go to the toilet and cry my heart out so that she does not see my tears. (65-year-old)

\section{Spiritual and religious issues}

All of the participants in this study identified themselves as Christians. Amongst the participants there was a sense of great faith in God, and they found great strength in prayer and in trust in God:

I was hurting but at the end I said God knows why, we all go through such challenges. But we consoled ourselves by the fact that she suffered through her illness and that it was God's will. There was nothing we could do further, she was 91 years old, she was old enough. We thank God that she lived to see her grand- and great grandchildren. (68-year-old)

But you can't understand God's thoughts and ways. What God loves, you also love it too, and the very same thing that you love, he takes it away from you. (73-year-old)

\section{Discussion}

Experiences of the death and dying of family members were sought through in-depth interviews with 10 elderly women. Findings show that the elderly experience multiple deaths of family members. Some older adults can develop a resiliency to coping with death due to the number of deaths encountered. ${ }^{8}$ Ageing is associated with a higher risk of the death of close family members, yet few studies have investigated the impact of such losses on different health outcomes, either by type of loss or by the combined losses. ${ }^{18}$ The death of a loved one is among the most stressful of all life events. ${ }^{1}$ Although the elderly often experience the death of loved ones at higher frequency than young adults, ${ }^{6}$ it cannot be assumed that this frequency establishes a readiness or ability to handle these experiences and to grieve successfully.

The experience of grief was pronounced when family members suffered pain before dying. This was also increased when they felt helpless to alleviate the pain. The elderly experience the widest variety of bereavement in terms of types of relationship to the deceased. ${ }^{6}$ This study shows that greatest sorrow was experienced where participants lost adult offspring. The bereavement literature often states that the death of a child is more detrimental than other familial bereavements. ${ }^{18}$ According to Gijzen et al. ${ }^{4}$ the death of a child is an enormous tragedy for both the parents and other family members.

Participants also experienced anxiety about impending death, particularly when multiple deaths took place and where they had to anxiously observe their family members' condition deteriorating. Death anxiety is a multifaceted construct that is difficult to define, but it has been conceptualised to include fear of death of others, and fear of dying, and it may manifest in avoidance or denial. ${ }^{19}$ Often participants protected the dying and other family members from sorrow by hiding their tears. According to Ekore and Lanre-Abass ${ }^{3}$ even the dying person goes through periods of fear and grief once the inevitability of death becomes apparent. Most people who lose a family member experience a wide variety of psychological symptoms, such as sadness, anxiety and anger, and also physical pain, reflected by phrases such as having 'a broken heart', ${ }^{\prime 9}$ as was observed in this study.

The intensity of parental grief is related to a number of factors, such as the coping strategies of the parents and the circumstances surrounding the death. ${ }^{4}$ Cultures vary widely regarding the magnitude to which death anxiety is expressed. Some cultures appear to manage the idea of dying comparatively well, so much so that they are referred to as death-affirming societies; in other cultures, aversion to the idea of dying is so strong that they can be classified as death-denying or death-defying cultures. ${ }^{19}$ 
Amongst the participants there was a sense of great faith in God's power, and that He was in control and they could do nothing. In most cases death is often looked at from both religious and cultural perspectives in Africa. ${ }^{2}$ Religion is said to help provide meaning and answers, and to affirm powerlessness. This phenomenon was found in a study on death and dying amongst the Sudanese community living in Australia, who found great strength in prayer and trust in God and the Bible, saying that God had given them courage in times of adversity, and that when faced with death and illness, prayer helps. ${ }^{20}$

\section{Conclusion}

In this study a phenomenological approach was used to gain greater insight into the grieving experiences of elderly women who have lost family members. Participants were exposed to multiple deaths of the people around them. Grieving was more pronounced when an adult offspring was lost. They experienced death anxiety regarding the impending death of family, which was exacerbated by the sorrow of observing family members suffering from pain, and of losing family members in their presence. The reaction to this experience was still eminently painful even as the study was conducted. The findings show that the grieving process of the elderly is not different from that of any other age group. This affirms that it cannot be assumed that multiple death experiences establish their readiness or ability to handle these experiences and to grieve successfully. It can be concluded that the grieving process of the elderly is not different from that of any other age group and that they will also require the type of support and assistance considered for younger persons in times of grieving.

Ethical considerations - Ethical clearance was obtained from Sefako Makgatho University Research and Ethics Committee (Reference number: MREC/H/305/2013).

Disclosure statement - No potential conflict of interest was reported by the author.

Funding - The author declares that she has no financial or personal relationship(s) which may have inappropriately influenced her in writing this paper.

\section{References}

1. Carr D. Death and dying in the contemporary United States: what are the psychological implications of anticipated death? Soc Pers Psychol Compass 2012;6(2): 184-195. doi:10.1111/j.1751-9004.2011.00416.x.

2. Sinoff G. Thanatophobia (death anxiety) in the elderly: The problem of the child's inability to assess their own parent's death anxiety state. Front Med (Lausanne) [online] 2017 Feb 27. doi:10.3389/fmed.2017. 00011. PMCID: PMC5326787.

3. Ekore Rl, Lanre-Abass B. African cultural concept of death and the idea of advance care directives. Indian J Palliat Care. 2016 OctDec;22(4): 369-72. doi:10.4103/0973-1075.191741.
4. Gijzen S, L'Hoir MP, Boere-Boonekamp MM, et al. How do parents experience support after the death of their child? BMC Pediatrics. 2016;16: 245. doi:10.1186/s12887-016-0749-9.

5. Shear MN, Ghesqueire A, Katzke M. Bereavement and complicated grief in older adults. In Lavretsky $H$, Sajatovic $M$, Reynolds CF, editors. Late life mood disorders. New York: Oxford University Press; 2013, p. 206-19.

6. Shah SN, Meeks S. Late-life bereavement and complicated grief: A proposed comprehensive framework. Aging \& Mental Health 2012;16(1): 39-56. doi:10.1080/13607860.2011.605054.

7. Reynolds CF, Stack J, Houle J. Healing emotions after loss (HEAL): diagnosis and treatment of complicated grief. Pittsburgh: University of Pittsburgh School of Medicine; 2011 [cited 2017, Nov 2]. Available from: http://hea;study.org/wp-content/uploads/2010/ 10/S270-Synergies_GR Spring_2011PDF

8. Newson RS, Boelen PA, Hek K, et al. The prevalence and characteristics of complicated grief in older adults. J Affect Disord 2011;132 (2): 231-8. doi:10.1016/j.jad.2011.02.021.

9. Hashim SM, Eng TC, Wahab S. Bereavement in the elderly: The role of primary care. Mental Health Fam Med. 2013;10(3): 159-162.

10. Silverstein M, Giarrusso R. Aging and family life: a decade review. J Marriage Fam. 2010, Oct;72(5): 1039-58. doi:10.1111/j.1741-3737. 2010.00749.x

11. Shear MK, Ghesquiere A, Glickman K. Bereavement and Complicated Grief. Curr Psychiatry Rep. 2013, November;15(11): 206-19. doi:10. 1007/s11920-013-0406-z.

12. Keyes KM, Pratt C, Galea S, et al. The burden of loss: unexpected death of a loved one and psychiatric disorders across the life course in a national study. Am J Psychiatry 2014;171(8): 864-871. doi:10.1176/appi.ajp.2014.13081132.

13. Streubert HJ, Carpenter DR. Qualitative Research in Nursing Advancing the Humanistic Imperative. 5th ed.. Philadelphia, PA: Lippincott Williams \& Wilkins; 2011. p. 2011.

14. De Vos AS, Strydom H, Fouche CB, et al. Research at Grass Roots for the Social Sciences and Human Service Profession. 4th ed.. Pretoria: Van Schaik; 2011.

15. Burns N, Grove, SK The practice of Nursing Research. Conduct, Critique and Utilization. 8th Ed. Raleigh, NC: Elsevier eBook on VitalSource; 1993.

16. Vaismoradi $\mathrm{M}$, Jones J, Turunen $\mathrm{H}$, et al. Theme development in qualitative content analysis and thematic analysis. J Nurs Educ Prac. 2016;6(5): 100-10.

17. Braun V, Clarke V. Using thematic analysis in psychology. Qualitative Research in Psychology. 2006;3(2): 77-101. ISSN: 1478-0887. Available from: http://eprints.uwe.ac.uk/1173510.1191/ 1478088706qp063oa

18. Bratt A. Surviving the loss of a child, a spouse, or both: Implications on life satisfaction and mortality in older ages [doctoral dissertation]. Växjö, Sweden: Department of Psychology, Linnaeus University; 2016 ISBN 978-91-88357-16-8.

19. Gire J. How death imitates life: Cultural influences on conceptions of death and dying. Online Read Psychol Cult. 2014;6(2): 2.

20. Sneesby L, Satchell R, Good P, et al. Death and dying in Australia: perceptions of a Sudanese community. J Adv Nurs 2011;67(12): 26962702. doi:10.1111/j.1365-2648.2011.0557x.Epub 2011 Aug11.

Received: 29-11-2017 Accepted: 6-05-2018 